\title{
Spontaneous Immunoglobulin A Secretion and Lack of Mitogen- responsive B Cells in Systemic Lupus Erythematosus
}

\author{
Osamu Saiki, Yukihiko Saeki, and Susumu Kishimoto \\ Third Department of Internal Medicine, Osaka University Medical School, Osaka, Japan 553
}

\begin{abstract}
In an analysis of lymphocyte functions of systemic lupus erythematosus (SLE) patients, B cell abnormalities such as a lack of mitogen-responsive $B$ cells and a predominance of spontaneous IgA-secreting cells (SC) were found.

Lymphocyte functions of 20 SLE patients were studied. Impaired proliferative response to B cell mitogen, Staphylococcus aureus strain Cowan I (Cowan I), was observed, whereas the response to $\mathbf{T}$ cell mitogen phytohemagglutinin was normal. High levels of spontaneous IgA-SC were observed in SLE patients $\left(>10^{2}\right.$ cells $/ 10^{4}$ peripheral blood mononuclear cells [PBMC]), whereas spontaneous IgM-, IgG-, or IgE-SC were not proportionately increased. The number of spontaneous IgA-SC decreased with time in culture and became undetectable by day 5 of culture. In contrast, spontaneous immunoglobulin- (IgM, IgG, and IgA) SC were not observed in healthy volunteers ( $<10$ cells/ $10^{4}$ PBMC). Moreover, in SLE patients failure of induction of immunoglobulin-secreting cells (ISC) was observed when B cells were stimulated by Cowan I and B cell differentiation factor at any day tested, whereas ISC were induced in healthy volunteers on day 6 of culture. Depletion of $T$ cells or macrophages did not affect the results obtained.

These results suggest that the abnormalities observed in SLE B cells are not due to the in vitro direct effects of suppressor macrophages or suppressor $T$ cells, and that the condition of the predominance of spontaneous $\mathrm{IgA-SC}$ and the unresponsiveness to exogenous stimulation may be emblematic of hyperactive $B$ cells in SLE.
\end{abstract}

\section{Introduction}

In vitro assessment of lymphocyte function is of crucial importance in the analysis of the pathogenesis of disease with immunologic dysfunctions, such as immunodeficiency, autoimmune, and lymphoproliferative diseases.

Systemic lupus erythematosus (SLE) ${ }^{1}$ is a disease characterized by disordered immune regulation. Hyperactive B cells are known to synthesize excessive amount of autoantibodies $(1,2)$

\footnotetext{
Address reprint requests to Dr. Saiki.

Received for publication 28 August 1984 and in revised form 7 June 1985.
}

1. Abbreviations used in this paper: $\mathrm{BCDF}, \mathrm{B}$ cell differentiation factor; Cowan I, Staphylococcus aureus strain Cowan I; FCS, fetal calf serum; ISC, immunoglobulin-secreting cell(s); PBMC, peripheral blood mononuclear cell(s); PFC, plaque-forming cell(s); PHA, phytohemagglutinin; PWM, pokeweed mitogen; SLE, systemic lupus erythematosus; TdR; thymidine.

J. Clin. Invest.

(c) The American Society for Clinical Investigation, Inc.

$0021-9738 / 85 / 11 / 1865 / 06 \$ 1.00$

Volume 76, November 1985, 1865-1870 and other immunoglobulins $(3,4,5,6)$. In addition, abnormalities of $\mathrm{T}$ cell subsets, particularly a deficiency of suppressor $\mathrm{T}$ cells $(7,8,9,10)$, or abnormalities of macrophages $(11,12)$ were reported to have association with this B cell hyperactivity. However, it has been unclear whether the B cell hyperactivity in SLE is independent of the abnormalities in $T$ cells or macrophages and whether the B cell hyperactivity may preceed or result from the other cell abnormalities.

In recent years, advances in the therapy for SLE made it possible to decrease death from the renal failure. Consequently the survival time of the SLE patients has increased $(13,14)$. However, infection has always been acknowledged as a major factor in morbidity and mortality suggesting the presence of an immunodeficient state in this disease (15).

Previously, we described methods to detect B cell functions of proliferation and differentiation to immunoglobulin-secreting cells (ISC) separately with either Staphylococcus aureus strain Cowan I (Cowan I) or B cell differentiation factor (BCDF) (16), and also showed three distinct stages of $B$ cell defects in common variable immunodeficiency (17).

In the present study, we have investigated the B cell functions of proliferation and differentiation to ISC in SLE patients and found such B cell abnormalities as a lack of mitogen-responsive $\mathrm{B}$ cells and a predominance of spontaneous IgA-SC.

\section{Methods}

Cell preparations. Peripheral blood mononuclear cells (PBMC) of patients with SLE and normal adult volunteers were obtained by centrifuging heparinized venous blood on Ficoll-Hypaque and three washes in Hanks' balanced salt solution (HBSS). B and T cells were separated by one or two cycles of rosetting with neuraminidase-treated sheep erythrocytes, followed by Ficoll-Hypaque centrifugations (16). Adherent cells were partially depleted by incubation for $4 \mathrm{~h}$ on petri dishes in culture medium (RPMI-1640) containing penicillin, streptomycin, $0.2 \mathrm{mM}$ glutamine, and $10 \%$ fetal calf serum (FCS). Contamination of monocytes or T cells in the B cell fractions was $<1 \%$ by esterase staining and $<0.5 \%$ by OKT 3 monoclonal antibody, respectively.

Cell culture. All cultures were carried out in RPMI-1640 medium supplemented with $100 \mathrm{U}$ of penicillin $/ \mathrm{ml}, 100 \mu \mathrm{g}$ of streptomycin $/ \mathrm{ml}$, $0.2 \mathrm{mM}$ glutamine, and 10\% FCS (Sterile Systems, Logan, UT).

Cells were cultured in flat-bottomed microtiter plates (3040, Falcon Plastics Co., Oxnard, CA) in triplicate with each microwell containing $2 \times 10^{5}$ cells in $0.2 \mathrm{ml}$ of culture medium. Mitogen dissolved in HBSS or an equivalent volume of HBSS as control was added to the wells, and they were incubated for (a given number of days) or $1-8 \mathrm{~d}$ at $37^{\circ} \mathrm{C}$ in a humidified atmosphere of $5 \% \mathrm{CO}_{2}$ and $95 \%$ air. At the end of the incubation, cells were washed and resuspended in HBSS for assay.

Mitogens. Pokeweed mitogen (PWM) (Grand Island Biological Co. Grand Island, NY), phytohemagglutinin (PHA) (Difco Laboratories, Detroit, MI), and Cowan I ( $10 \% \mathrm{vol} / \mathrm{vol}$ formaldehyde and heat-killed; Calbiochem-Behring Corp., San Diego, CA) were used.

$\left[{ }^{3} \mathrm{H}\right]$ thymidine (TdR) incorporation assay for lymphocyte mitogenesis. Cells were cultured in flat-bottomed microtiter plates $(3040$, Falcon Plastics) in triplicate, with each microwell containing $2 \times 10^{5}$ cells in $0.2 \mathrm{ml}$ of culture medium. Final concentration of PHA was $1 \mu \mathrm{l} / \mathrm{ml}$ and 
that of Cowan I was $0.01 \% \mathrm{vol} / \mathrm{vol} .1 \mu \mathrm{Ci}$ of $\left[{ }^{3} \mathrm{H}\right] \mathrm{TdR}(6 \mathrm{Ci} / \mathrm{mmol}$, New England Nuclear, Boston, $\mathrm{MA} ; 1 \mathrm{Ci}=3.7 \times 10^{10}$ becquerels) was added for the last $4 \mathrm{~h}$. The cells were harvested and washed on glass filters, and $\left[{ }^{3} \mathrm{H}\right] \mathrm{TdR}$ incorporation was determined by liquid scintillation counting (18).

Assay for spontaneous ISC. Cells separated by Ficoll-Hypaque were suspended in HBSS for the assay. Immediately after cell separation, ISC were examined by reverse hemolytic plaque assay (16).

Assay for ISC. ISC were detected with a previously described reverse hemolytic plaque assay with protein A-coated sheep erythrocytes (19). Specific IgM, IgG, and IgA plaque-forming cells (PFC) were detected (20) by using the IgG fraction of rabbit anti-human IgM, IgG, IgA, and polyspecific anti-Ig antibodies (Boehringer-Mannheim Biochemicals, Indianapolis; IN, Miles-Yeda, Israel; DAKO, Accurate Chemical \& Scientific Corp, Hicksville, NY). Each specificity was tested with ISC lines (21) BM (IgM), CESS (IgG), and DAKIKI clone 1 (IgA). No cross-reactivity was observed as shown in Table I. Preparations of class-specific antibodies were chosen to give maximum plaques with the homologous cell line and no plaque with the other lines. Anti-IgE antibody was prepared by the immunization of rabbits with purified IgE and the antiserum was made monospecific by extensive adsorption on a normal IgG-conjugated Sepharose column, and the anti-IgE antibody was specifically purified by affinity chromatography through an IgE Sepharose column (22).

Induction of ISC. Peripheral blood lymphocytes (PBL) were cultured as above for a given number of days with PWM $(0.025 \%)$ plus Cowan I $(0.01 \%)$, or in some experiments B cells were cultured with Cowan I $(0.01 \%)$ plus BCDF for 6 or $7 \mathrm{~d}(16)$. Cells were washed and resuspended in HBSS for the assay of ISC.

$B C D F$. Mononuclear cells were isolated from a patient's spleen which was pathologically not involved. The cells were irradiated with 1,000 rads $\left(1 \mathrm{rad}=2.58 \times 10^{4} \mathrm{Ci} / \mathrm{kg}\right)$ to enhance the factor production (23) and cultured at $2 \times 10^{5}$ cells per $\mathrm{ml}$ in $1 \%$ FCS with $0.25 \%$ PWM for 2 d. The supernatant was concentrated 20 -fold by Amicon pressure filtration (Amicon Corp., Danvers, MA) and the material precipitating between 33 and $88 \%$ (vol/vol) ammonium sulfate was applied for fractionation on a Sephadex G-100 column as described previously (23). The 15,00020,000 mol wt material is designated BCDF.

Patients. 20 SLE patients were studied who all fulfilled the American Rheumatism Association criteria for SLE (24). There were 3 men and 17 women ranging in age from 20 to $45 \mathrm{yr}$. Most of the patients were in an inactive state of the disease, but four patients were in the active state. All patients were receiving corticosteroids ranging in dose from 2.5 to $20 \mathrm{mg}$ of prednisolone per day. In addition, two patients had received cyclophosphamide or azathiopurine previously, but not at the time of this study.

\section{Results}

Lack of mitogenic response to B cell mitogens in SLE. PBMC of healthy volunteers and SLE patients were obtained by FicollHypaque centrifugation. PBMC were stimulated for $72 \mathrm{~h}$ in the

Table I. Specificity of the Immunoglobulin Isotype-specific Antibodies Used

\begin{tabular}{llll}
\hline ISC line & Anti-IgM & Anti-IgG & Anti-IgA \\
\hline & $P F C / 10^{4}$ PBMC & $P F C / 10^{4}$ PBMC & $P F C / 10^{4} P B M C$ \\
BM (IgM) & $88 \pm 7$ & $<1$ & $<1$ \\
CESS (IgG) & $<1$ & $235 \pm 29$ & $<1$ \\
DAKIKI (IgA) & $<1$ & $<1$ & $166 \pm 16$
\end{tabular}

ISC were detected by reverse plaque assay. Each cell line is secreting a single isotype of immunoglobulin (21).

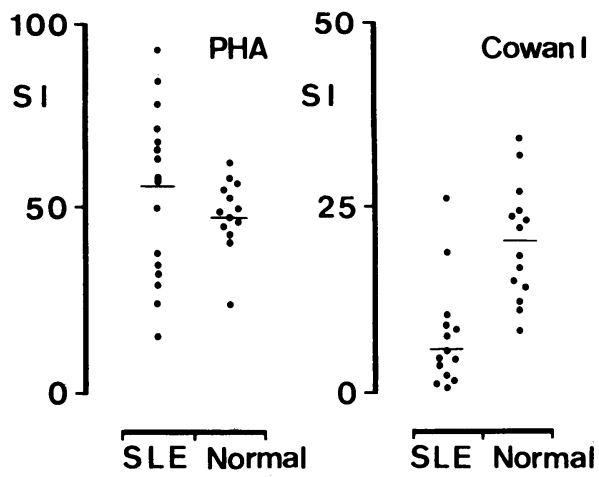

Figure 1. Lack of proliferative response to B cell mitogen in SLE. PBMC were stimulated by either PHA or Cowan I and proliferative responses were assayed by $\left[{ }^{3} \mathrm{H}\right] \mathrm{TdR}$ incorporation on day 3 of culture. The response of SLE cells to Cowan I was significantly depressed compared to normals $(P<0.005)$. SI, stimulation index.

presence of either T cell mitogen (PHA) or B cell mitogen (Cowan I). Lymphocytes of healthy volunteers showed strong mitogenic responses to both PHA and Cowan I. Similarly, strong mitogenic responses to PHA were also observed in PBL of the SLE patients, whereas mitogenic responses to Cowan I were absent or extremely weak in most patients as shown in Fig. $1(P<0.005)$.

Additional experiments were undertaken to determine whether the impaired response to Cowan I was due to the effects of T cells or macrophages. Partially purified B cells, depleted of $T$ cells and macrophages, were cultured either with Cowan I or PHA to determine DNA synthesis on day 3 of culture. No mitogenic response to Cowan I was observed in SLE B cells, whereas a striking mitogenic response to Cowan I was obtained in healthy controls (Table II). As a control for the effects of prednisolone therapy, the responses of rheumatoid arthritis and asthma patients treated with the corticosteroid were normal (Table II). These results suggest that weak or no mitogenic responses to B cell mitogen observed in SLE patients are due to neither the direct effects of suppressor $\mathrm{T}$ cells nor suppressor macrophages.

Predominance of spontaneous IgA-SC in SLE. ISC were examined at days 0-6 after culture of PBMC in the absence of Cowan I or PWM by reverse plaque assay (Fig. 2). Many spontaneous IgA-SC ( $>10^{2}$ cells $/ 10^{4}$ PBMC) were observed on days 0 and 1 in SLE patients, whereas there were few IgM- and IgG-

Table II. Lack of Mitogenic Response to Cowan I in SLE B Cells

\begin{tabular}{lcccc}
\hline & \multicolumn{3}{l}{ Stimulation } & \\
\cline { 2 - 5 } Donor & - & Cowan I & PHA \\
\hline & $c p m(S I)$ & $c p m(S I)$ & $c p m(S I)$ \\
SLE $(n=15)$ & $462 \pm 34$ & $509 \pm 48$ & $(1.10)$ & $485 \pm 92(1.05)$ \\
$\begin{array}{l}\text { Healthy controls } \\
(n=15)\end{array}$ & $794 \pm 57$ & $16,972 \pm 3,135(21.4)$ & $811 \pm 74(1.02)$
\end{tabular}

Partially purified B cells, depleted of $\mathrm{T}$ cells and macrophages, were stimulated and $\left[{ }^{3} \mathrm{H}\right] \mathrm{TdR}$ incorporation was assayed on day 3 of culture.

Contamination of $\mathrm{T}$ cells and macrophages in the B cell fractions was $<0.5 \%$ and $1 \%$, respectively (Methods).

Stimulation index (SI) to Cowan I of rheumatoid arthritis and asthma patients who had received steroid therapy (prednisolone: $10 \mathrm{mg} / \mathrm{d}$ ) for $>5 \mathrm{yr}$ was 18.7 and 20.5 , respectively. 

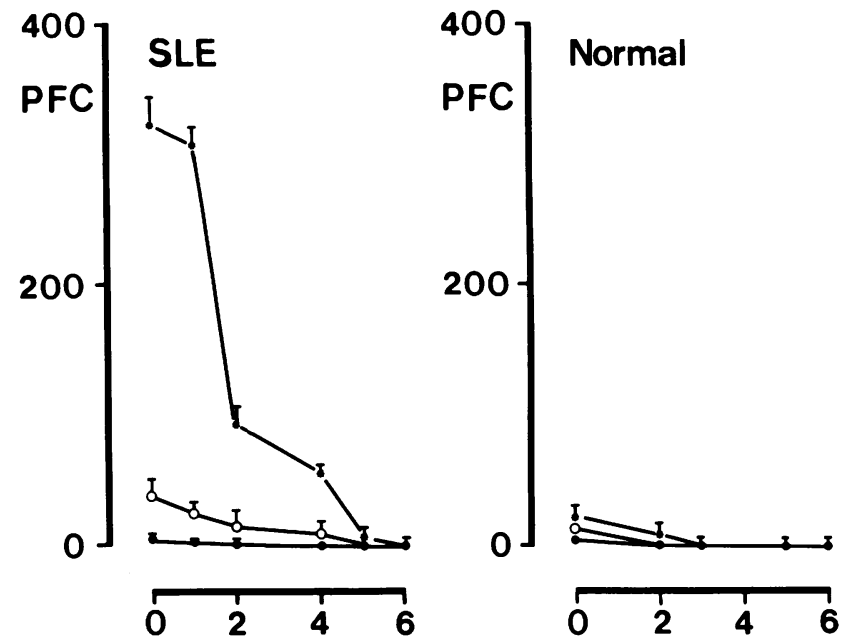

Figure 2. Kinetics of spontaneous ISC. Spontaneous IgM-(•), IgG-(0), and IgA-(*) SC were detected on given days by reverse plaque assay (ISC/10 4 initial PBMC). Abscissa expresses days of culture.

$\mathrm{SC}$ at any day tested. The number of IgA-SC diminished with time and became undetectable by day 5 . Only a few spontaneous ISC were observed in healthy controls.

Other experiments were undertaken to determine the isotype distribution of spontaneous ISC. Spontaneous ISC were determined on day 0 at a higher cell density and in certain experiments, IgM, IgG, IgA, and IgE PFC were determined in addition to total ISC (Table III). It was found that SLE patients had high numbers of spontaneous ISC when compared with a healthy control. The number of spontaneous IgA-SC was much greater than that of IgG- and IgM-SC in SLE. Although the numbers of spontaneous IgG- and IgM-SC were low, they were also increased in some SLE patients when compared with healthy controls. In healthy controls, the small numbers of spontaneous ISC were mainly of the IgA and IgG isotype. Both in SLE patients and healthy controls, spontaneous IgE-SC were not even detected in $10^{7}$ cells assayed. The number of spontaneous ISC determined by the polyspecific anti-Ig reagent was as great as the sum of the numbers determined by each monospecific anti-Ig reagent.

Further experimentation to examine many other SLE patients was carried out in order to confirm these observations. In most SLE patients, high numbers of spontaneous IgA-SC were observed, and IgM- and IgG-SC were low or undetectable (Fig. 3 ). In healthy controls, low numbers of spontaneous ISC were

Table III. Isotype Distribution of Spontaneous ISC

\begin{tabular}{ccclll}
\hline Donor & IgM-SC & IgG-SC & IgA-SC & IgE-SC & Polispecific ISC \\
\hline & ISC $/ 10^{5}$ & initial PBMC & & $\begin{array}{l}I S C / 10^{7} \\
P B M C\end{array}$ & $\begin{array}{l}I S C / 10^{5} \\
P B M C\end{array}$ \\
& & & & & not done \\
SLE & $15 \pm 5$ & $110 \pm 14$ & $6,240 \pm 226$ & $<1$ & \\
patient 1 & $(0.3 \%)^{*}$ & $(1.7 \%)$ & $(98.0 \%)$ & $(0 \%)$ & \\
SLE & $17 \pm 4$ & $425 \pm 53$ & $1,129 \pm 65$ & $<1$ & $1,451 \pm 214$ \\
patient 2 & $(1.1 \%)$ & $(27.0 \%)$ & $(71.9 \%)$ & $(0 \%)$ & \\
Healthy & $3 \pm 1$ & $28 \pm 9$ & $57 \pm 6$ & $<1$ & $94 \pm 11$ \\
control & $(3.4 \%)$ & $(31.8 \%)$ & $(64.8 \%)$ & $(0 \%)$ & \\
& & & & &
\end{tabular}

Spontaneous ISC were detected on day 0 by reverse plaque assay as in Fig. 2 .

* Percent of total spontaneous ISC.

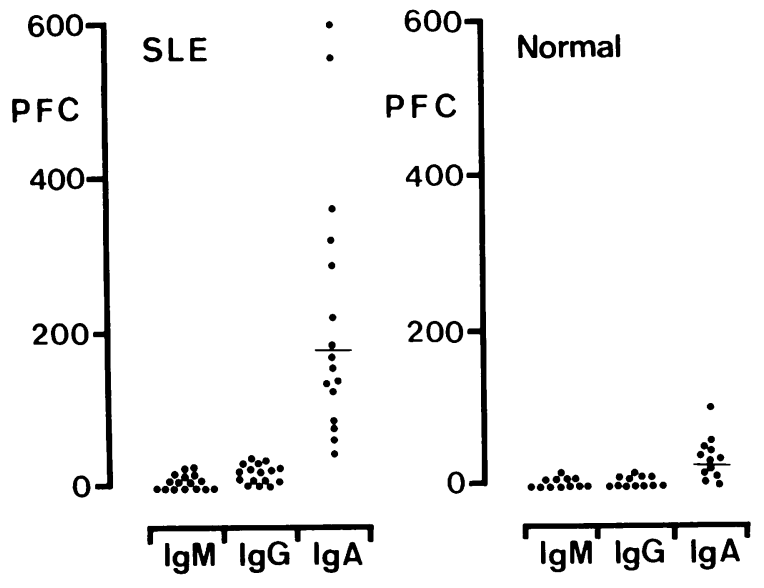

Figure 3. Spontaneous ISC in SLE. Spontaneous IgM-, IgG-, and IgASC from 16 SLE patients and 12 normals were detected immediately after cell separation by reverse plaque assay (ISC/104 initial PBMC). IgA-SC were significantly elevated in SLE patients $(P<0.005)$.

observed and were also predominantly of $\operatorname{IgA}$ class. In certain experiments, cytoplasmic Ig-positive cells were examined to compare with spontaneous IgA-SC. In a SLE patient, $3.1 \%$ of PBMC were cytoplasmic IgA-positive, whereas cytoplasmic IgG or IgM-positive cells were $<0.5 \%$. In PBMC of a healthy donor, cytoplasmic IgA-positive cells were $<0.20 \%$. These results suggest that IgA-containing as well as IgA-SC predominate in SLE patients.

Failure of induction of ISC in SLE. The ability of B cells to differentiate to ISC in vitro was examined. PBMC were cultured with Cowan I and PWM, which are known to induce a high level of ISC (16), and ISC were determined on day 6 of culture by reverse plaque assay. Many ISC were detected in healthy volunteers (Fig. 4). In contrast, very low numbers of ISC were observed in the patients. The time course of the induction of ISC was investigated to determine whether different kinetics would account for the failure of induction of ISC in SLE. IgM-, IgG-, and IgA-SC were examined at days $0-8$. The greatest number of ISC was observed in healthy controls on day 6 (Fig. $5)$, whereas high levels of ISC induction were not observed in SLE. The high number of IgA-SC on day 0 were spontaneous

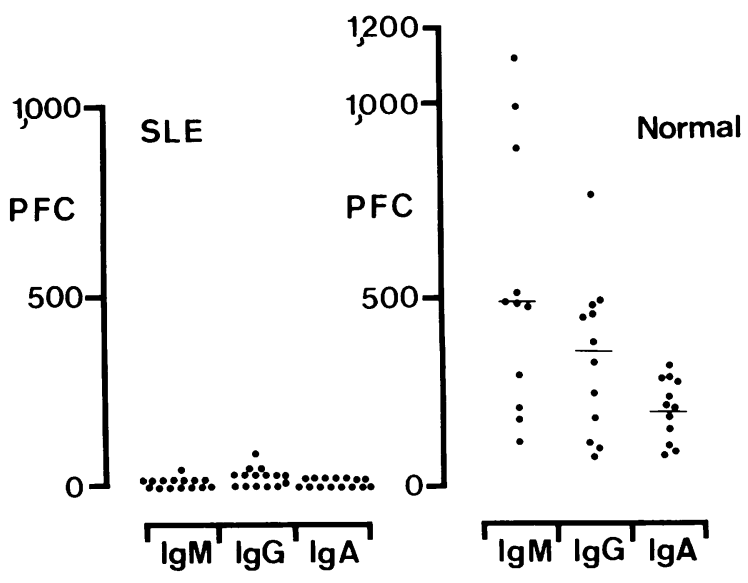

Figure 4. Failure of induction of ISC in SLE. PBMC were stimulated by PWM plus Cowan I (16) and ISC were detected by reverse plaque assay on day 6 of culture (ISC/104 initial PBMC). 


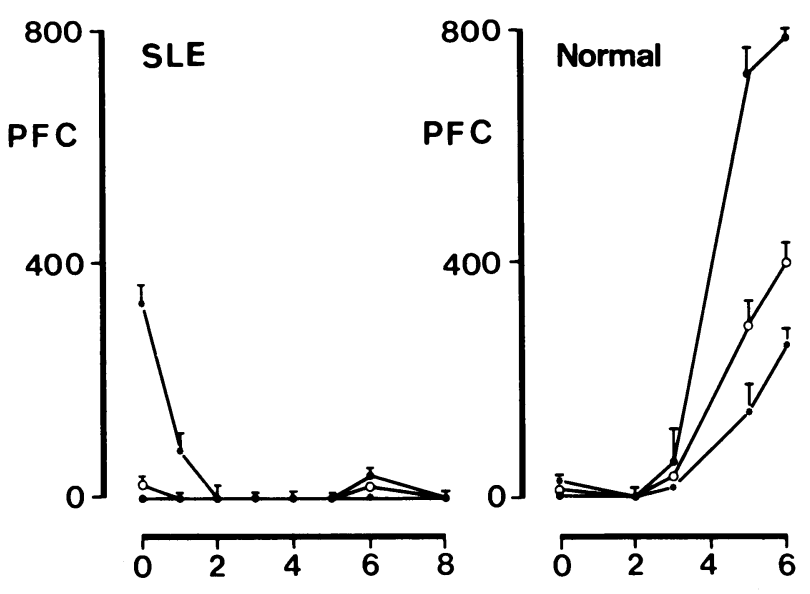

Figure 5. Kinetics of induction of ISC. PBMC were stimulated by PWM plus Cowan I (16) and IgM-(•), IgG-(0), and IgA-(*) SC were detected on given days (ISC/10 $0^{4}$ initial MNC). Abscissa expresses days of culture.

IgA-SC as shown in Fig. 2. These results eliminate the possibility that the failure to induce ISC in SLE patients by mitogens was due to a shift of the kinetics of Ig secretion.

Additional experiments were performed to determine whether the failure of differentiation to ISC was due to the effects of T cells or macrophages. Partially purified B cells, depleted of $T$ cells and macrophages, were cultured with Cowan I and partially purified BCDF (Table IV). ISC were assayed on day 6 of culture. Neither Cowan I nor BCDF alone succeeded in induction of ISC from both healthy and SLE B cells. A significant number of IgM-, IgG-, and IgA-SC were detected in healthy controls when stimulated with Cowan I and BCDF, whereas only few ISC were observed in SLE patients. Arthritis and asthma patients treated with prednisolone similarly to SLE patients showed normal ISC inductions (Table IV). These results suggest that the failure to induce ISC in SLE is not due to the in vitro direct effects of $\mathrm{T}$ cells or macrophages.

\section{Discussion}

The studies presented here were undertaken to examine the immunologic function of B cells obtained from patients with SLE. They were found to have such B cell abnormalities as impaired proliferative response to $B$ cell mitogens, predominance of spontaneous IgA-SC, and failure to differentiate to ISC when stimulated by Cowan I and BCDF.

Most spontaneous ISC in SLE patients were of the IgA isotype. To our knowledge, this has never been described in previous reports. Employing either the reverse plaque assay $(5,6,11,12$, $25,26)$ or radioimmunoassay (27), antigen-specific or antigennonspecific spontaneous $\mathrm{Ig}$ secretion was reported in SLE. In previous experiments by other investigators, IgG was documented to be the major isotype of Igs secreted. Using an antigennonspecific reverse plaque assay similar to ours, Ginsberg et al. (25) reported a mean of 13,805 ISC per $10^{6}$ cells, among which $74 \%$ secreted IgG, $10 \%$ IgM, and $22 \%$ IgA. Blaese et al. (26) detected a mean of 835 spontaneous ISC per $10^{6}$ cells in PBL among which $58 \%$ secreted $\mathrm{IgG}, 9 \% \mathrm{IgM}$, and $33 \% \mathrm{IgA}$, and Fauci et al. (6) also found the predominant isotype of spontaneous ISC to be IgG. In contrast, we found a mean of 15,300 ISC per $10^{6}$ cells, among which $>94 \%$ cells secreted the IgA isotype. It is uncertain why different results were obtained by the various investigators. It seems unlikely that anti-IgA antibody made a pseudo-plaque formation which we counted as IgA-SC. The specificity of anti-IgG, -M, and -A antibodies used for the reverse plaque assay was checked by each of the established cell lines that secrete only one isotype of Ig (21) (IgG-CESS, IgMBM, IgA-DAKIKI). No cross-reactivity was confirmed as shown in Table I, and microscopically each plaque had a single cell in the center. In preliminary experiments, most IgA plaques were inhibited by preabsorption of anti-IgA sera with human IgA, but not with IgM or IgG. Furthermore, different lots of antiIgM, anti-IgG, and anti-IgA sera were also examined to detect spontaneous ISC and comparable results were observed (data not shown). Cytoplasmic IgA-positive cells were also increased in SLE patients. These results clearly show that in our patients the predominant isotype of spontaneous ISC is IgA, but it remains uncertain why spontaneous IgA-SC predominates in this disease. It is possible to assume that switch $\mathrm{T}$ cells $(28,29)$, which may. induce IgA secretion of B cells, are increased in SLE patients. In preliminary experiments, however, we could not prove this, because $T$ cells from SLE patients induced as many IgG- and IgM-SC as IgA-SC in control B cells.

Spontaneous Ig-secreting B cells detected by in vitro assay immediately after blood removal are believed to have been activated in vivo. It is also possible that mucosal gut-associated tissue such as Peyer's patch are stimulated to induce IgA-SC in SLE patients, inasmuch as precursors for IgA plasma cells are enriched in such tissues (29).

Table IV. Induction of ISC by Cowan I and BCDF in SLE B Cells

\begin{tabular}{|c|c|c|c|c|c|c|}
\hline \multirow[b]{3}{*}{ Stimulation } & \multicolumn{6}{|l|}{ Donor } \\
\hline & \multicolumn{3}{|c|}{ SLE patient } & \multicolumn{3}{|c|}{ Healthy control } \\
\hline & IgM-SC & IgG-SC & IgA-SC & IgM-SC & IgG-SC & IgA-SC \\
\hline & \multicolumn{3}{|c|}{$I S C / 10^{4}$ initial $P B M C$} & \multicolumn{3}{|c|}{$I S C / 10^{4}$ initial PBMC } \\
\hline- & $<1$ & $2 \pm 1$ & $13 \pm 1$ & $2 \pm 1$ & $4 \pm 1$ & $5 \pm 2$ \\
\hline Cowan I & $<1$ & $4 \pm 2$ & $7 \pm 2$ & $12 \pm 1$ & $18 \pm 3$ & $14 \pm 2$ \\
\hline BCDF & $2 \pm 1$ & $<1$ & $10 \pm 3$ & $18 \pm 2$ & $20 \pm 4$ & $15 \pm 2$ \\
\hline Cowan I + BCDF & $15 \pm 1$ & $25 \pm 3$ & $17 \pm 1$ & $244 \pm 8$ & $233 \pm 15$ & $206 \pm 5$ \\
\hline
\end{tabular}

Partially purified B cells (Methods) were stimulated with Cowan I and BCDF, and ISC were detected by reverse plaque assay on day 6 of culture. The numbers of induced IgM-SC with Cowan I and BCDF in rheumatoid arthritis and asthma patients who had received steroid therapy (prednisolone: $10 \mathrm{mg} / \mathrm{d}$ ) for $>5 \mathrm{yr}$ were $309 \pm 4$ and $216 \pm 17$, respectively. 
The levels of serum IgA and IgG are known to be high in SLE patients $(3,26)$, although spontaneous IgG-SC were not so numerous as IgA-SC in the present study. This contradiction may be partly explained by the short half-life of $\operatorname{IgA}$ in serum compared with that of IgG.

Despite the presence of hypergammaglobulinemia in many of these patients, they had a markedly suppressed capacity to generate ISC in vitro in response to the polyclonal B cell activators, Cowan I and BCDF. These observations are in agreement with those who have studied the PWM-induced Ig synthesis of PBMC from SLE patients (10-12, 25, 30-32). The diminished capacity of SLE B cells to differentiate into ISC in response to the polyclonal B cell activator could be accounted for by impaired helper $T$ cell activity $(25,30)$, enhanced suppressor macrophage activity $(11,12)$, or B cell abnormalities per se.

$B$ cells depleted of $T$ cells and macrophages and partially purified BCDF were used to exclude the regulatory influences of these cells in the present studies. SLE B cells failed to differentiate to ISC in response to Cowan I and BCDF, suggesting that the abnormalities observed are not due to the direct, in vitro effects of $\mathrm{T}$ cells or macrophages. These findings are in accord with those of others who showed B cell abnormalities by employing an antigen-specific or nonspecific Ig induction system with PWM $(31,32)$. We cannot deny the possibility that observed B cell abnormalities are due to the direct or indirect, in vivo effects of T cells, macrophages, and the disease process of SLE.

Studies on the activation of B lymphocytes in rabbits (33), mice (34), and humans (18) have revealed that at least two signals, proliferative and differentiative signals, are required for induction of Ig secretion. SLE B cells showed unresponsiveness to not only a proliferative signal (Cowan I), but also a differentiative signal ( $T$ cells or BCDF). In the present studies, SLE B cells were found to be unresponsive to in vitro exogenous stimulation whereas they spontaneously secreted IgA with high frequency. These results suggest that peripheral SLE B cells are in so-called hyperactive or activated state as previously shown by others $(2,5)$. The reason why these hyperactive $\mathbf{B}$ cells are generated is not yet clear, but several possibilities could be considered. It is probable that loss of suppressor T cell subset (7-9), or several autoantibodies $(1,2)$ may cause the generation of these state. In this study a decrease of Ts subsets, Leu $2 \mathrm{a}$, was also observed in most of the patients (data not shown) as was reported by others (7-9). It is also conceivable that unknown serum factor(s) at the onset of illness may trigger $B$ cell activation and then hyperactive B cell may not respond to further stimulation in vivo or in vitro $(2,5,32)$.

It is unlikely that the abnormalities observed in the present studies were due to the effects of corticosteroid therapy which most of the patients were receiving, because the patients with rheumatoid arthritis and bronchial asthma who had received similar corticosteroid therapy had normal responsiveness to in vitro stimulation with Cowan I and BCDF (Tables II and IV). It is still unclear why many spontaneous IgA-SC appear in the peripheral blood of SLE patients in whom this phenomenon may have been as yet unappreciated. We hope that these observations will provide the basis for further and more sophisticated delination of immunoregulatory abnormalities in this disease.

\section{Acknowledgments}

We thank Dr. P. Ralph (Cetus) for critical review of the manuscript.

This work was supported in part by grants from the Ministry of
Education, Science and Culture, the Ministry of Health and Welfare, and the Mochida Memorial Foundation for Medical and Pharmaceutical Research.

\section{References}

1. Kunkel, H. G., and E. M. Tan. 1964. Autoantibodies and disease. Adv. Immunol. 4:355-395.

2. Decker, J. L., A. D. Steinberg, J. L. Reinertsen, P. H. Plotz, J. E. Balow, and J. H. Klippel. 1979. Systemic lupus erythematosus: evolving concept. Ann. Intern. Med. 9:587-604.

3. McKelvey, E. M., and J. L. Fahey. 1965. Immunoglobulin changes in disease: quantitation on the basis of heavy polypeptide chains $\mathrm{IgG}$ $(\gamma \mathrm{G})$, IgA $(\gamma \mathrm{A})$, and $\operatorname{IgM}(\gamma \mathrm{M})$, and of light polypeptide chains type $\mathrm{K}$ (I) and type L (IL). J. Clin. Invest. 44:1778-1787.

4. Estes, D., and C. L. Christian. 1971. The natural history of lupus erythematosus by prospective analysis. Medicine (Baltimore). 50:85-95.

5. Budman, D. R., E. B. Merchant, A. D. Steinberg, B. Doft, M. E. Gershwin, E. Lizzio, and J. P. Reeves. 1977. Increased spontaneous activity of antibody-forming cells in the peripheral blood of patients with active SLE. Arthritis Rheum. 20:829-833.

6. Fauci, A. S., and H. M. Moutsopoulos. 1981. Polyclonally triggered $B$ cells in the peripheral blood and bone marrow of normal individuals and in patients with systemic lupus erythematosus and primary Sjögren's syndrome. Arthritis Rheum. 24:577-584.

7. Bresnihan, B., and H. E. Jasin. 1977. Suppressor function of peripheral blood mononuclear cells in normal individuals and in patients with systemic lupus erythematosus. J. Clin. Invest. 59:106-116.

8. Horowitz, S., W. Borcherding, A. V. Moorthy, R. Chesney, H. Schulte-Wassermann, R. Hong, and A. Goldstein. 1977. Induction of suppressor $\mathrm{T}$ cells in systemic lupus erythematosus by thymosin and cultured thymic epithelium. Science (Wash. DC). 197:999-1001.

9. Sagawa, A., and N. I. Abdou. 1978. Suppressor-cell dysfunction in systemic lupus erythematosus: cells involved and in vitro correction. J. Clin. Invest. 62:789-796.

10. Fauci, A. S., A. D. Steinberg, B. F. Haynes, and G. Whalen. 1978. Immunoregulatory aberrations in systemic lupus erythematosus. J. Immunol. 121:1473-1479.

11. Tsokos, G. C., and J. E. Balow. 1981. Spontaneous and pokeweed mitogen-induced plaque-forming cells in systemic lupus erythematosus. Clin. Immunol. Immunopathol. 21:172-183.

12. Burns, G. F., C. L. Librach, I. H. Frazer, I. J. Kronborg, and I. R. Mackeay. 1982. Spontaneous reverse hemolytic plaque formation. III. Monocyte-mediated suppression of elevated plaque formation in autoimmune disease. Clin. Immunol. Immunopathol. 24:386-395.

13. Ginzler, E., and H. Diamond. 1979. A multicenter study of survival in systemic lupus erythematosus. Arthritis Rheum. 22:613. (Abstr.)

14. Wallace, D. J., T. Podell, J. Weiner, J. Klinenberg, S. Forouzesh, and E. Dubois. 1981. Systemic lupus erythematosus-survival patterns. JAMA (J. Am. Med. Assoc.). 245:934-938.

15. Rosner, S., E. Ginzler, H. Diamond, M. Weiner, M. Schlesinger, J. Fries, C. Wasner, T. Medsger, G. Ziegler, J. Klippel, N. Hadler, D. Albert, E. Hess, G. Green, A. Grayzel, D. Worth, B. Hahn, and E. Barnett. 1982. A multicenter study of outcome in systemic lupus erythematosus. Arthritis Rheum. 25:612-617.

16. Saiki, O., and P. Ralph. 1981. Induction of human immunoglobulin secretion. I. Synergic effect of B cell mitogen Cowan I plus T cell mitogen or factors. J. Immunol. 127:1044-1047.

17. Saiki, O., P. Ralph, C. Cunningham-Rundles, and R. A. Good. 1982. Three distinct stages of B-cell defects in common varid immunodeficiency. Proc. Natl. Acad. Sci. USA. 79:6008-6012.

18. Saiki, O., T. Kishimoto, T. Kuritani, A. Muraguchi, and Y. Yamamura. 1980. In vitro induction of IgM secretion and switching to IgG production in human B leukemic cells with the help of T cells. J. Immunol. 124:2609-2614.

19. Gronowicz, E., A. Coutinho, and F. Melchers. 1976. A plaque assay for cells secreting Ig of a given type of class. Eur. J. Immunol. 6 : 588-590. 
20. Saiki, O., and P. Ralph. 1982. Induction of human immunoglobulin secretion. III. Inhibition of induction of IgG and IgA production in spleen but not peripheral blood cells by mitogenic antibody to IgM and IgD. Clin. Immunol. Immunopathol. 25:144-125.

21. Ralph, P. 1979. Functional subsets of human and murine B lymphocyte cell lines. Immunol. Rev. 48:107-121.

22. Deguchi, H., M. Suemura, A. Ishizaka, Y. Ozaki, S. Kishimoto, Y. Yamamura, and T. Kishimoto. 1983. IgE class-specific suppressor T cells and factors in human. J. Immunol. 131:2751-2756.

23. Saiki, O., and P. Ralph. 1983. Clonal differences in response to $T$ cell replacing factor (TRF) for IgM secretion and TRF receptors in human B lymphoblastoid cell line. Eur. J. Immunol. 13:31-34.

24. Tan, E. M., A. S. Cohen, J. F. Fries, A. T. Masi, D. J. McShance, N. F. Rothfield, J. G. Schaller, N. Talal, and R. J. Winchester. 1982. Revised criteria for the classification of systemic lupus erythematosus. Arthritis Rheum. 25:1271-1277.

25. Ginsburg, W. W., F. D. Finkelman, and P. E. Lipsky. 1979. Circulating and pokeweed mitogen-induced immunoglobulin secreting cells in systemic lupus erythematosus. Clin. Exp. Immunol. 35:76-88.

26. Blaese, R. M., J. Grayson, and S. D. Steinberg. 1980. Increased immunoglobulin-secreting cells in the blood of patients with active systemic lupus erythematosus. Am. J. Med. 69:345-350.

27. Morimoto, C., E. L. Reinherz, L. M. Nadler, J. A. Distaso, A. D. Steinberg, and S. F. Schlossman. 1982. Comparison in T- and Bcell markers in patients with Sjögren's and systemic lupus erythematosus. Clin. Immunol. Immunopathol. 22:270-278.
28. Elson, C. D., J. A. Heck, and W. Strober. 1979. T-cell regulation of murine IgA synthesis. J. Exp. Med. 149:632-643.

29. Kawanishi, H., L. E. Saltzman, and W. Strober. 1983. Mechanisms regulating IgA class-specific immunoglobulin production in murine gutassociated lymphoid tissues. I. T cells derived from Peyer's patches that switch slgM B cells to slgA B cells in vitro. J. Exp. Med. 157:433-450.

30. Delfraissy, J. F., P. Segond, P. Galanaud, C. Wallon, P. Massias, and J. Dormont. 1980. Depressed primary in vitro antibody response T helper cell defect and lack of defective suppressor cell function. J. Clin. Invest. 66:141-148.

31. Nies, K. M., R. H. Stevens, and J. S. Louie. 1981. Impaired immunoglobulin $\mathbf{M}$ synthesis by peripheral blood lymphocytes in systemic lupus erythematosus: a primary B cell defect. Clin. Immunol. Immunopathol. 19:118-130.

32. Nies, K., R. Boyer, R. Stevens, and J. Louie. 1980. Anti-tetanus toxoid antibody synthesis after booster immunization in systemic lupus erythematosus. Arthritis Rheum. 23:1343-1350.

33. Kishimoto, T., T. Miyake, Y. Nishizawa, T. Watanabe, and Y. Yamamura. 1975. Triggering mechanism of B lymphocytes. I. Effect of anti-immunoglobulin and enhancing soluble factor on differentiation and proliferation of B cells. J. Immunol. 115:1179-1184.

34. Parker, D. C., D. C. Wadsworth, and G. B. Schneider. 1980. Activation of murine B lymphocytes by anti-immunoglobulin is an inductive signal leading to immunoglobulin secretion. J. Exp. Med. 152: 138-150. 